\title{
Enhancing services provision in urban greenspaces through tourism promotion: the case of the private patios in Central America
}

\author{
A. González-García \& A. Gómez-Sal \\ Department of Ecology, University of Alcalá, Spain
}

\begin{abstract}
The provision of environmental services from ecosystems is a growing area of research encouraged by the Millennium Ecosystem Assessment of the United Nations. Nevertheless, the experiences of services evaluation from the perspective of ecology are still scarce. In many traditional Central American towns, patios provide a considerable provision of services for human wellbeing, both for the important surface that they occupy and for the naturalness that they maintain. In the present work we studied the provision of environmental services from patios in León (Nicaragua). Forty patios of different characteristics (from colonial to indigenous roots) were selected by a stratified sampling design. The study shows the importance of goods supply (mostly fruits), microclimatic regulation, recreational values and support for wildlife (birds, iguanas and native useful plants). A progressive fragmentation of dwelling space is affecting all services provision, especially fruits and wildlife, with lesser incidence in microclimatic regulation and recreational values. The incorporation of tourism based on patios as a developing tool is discussed in the context of services evaluation. This new function, which has been incorporated in the management of some pPlot patios, can stimulate owners to preserve the original valuable characteristics of patios, and at the same time, consolidate the provision of other more strategic and basic services for the whole community.
\end{abstract}

Keywords: services provision, private urban greenspaces, urban ecology, tourism and recreational services. 


\section{Introduction}

Natural, human-managed and disturbed ecosystems that are distributed worldwide provide a set of services to humans in different degrees and quantities, contributing to a significant part of their wellbeing [1]. This approach to study the ecosystems is relatively new [2] and acquired growing importance at the beginning of the present century in the context of global changes that affect the biosphere. The Millennium Ecosystem Assessment studied the consequences of global change on ecosystems at a broad (planetary) scale and also the reductions of services provision. However, there is an important unawareness about the functioning and accounting of ecosystem services and their spatial and temporal dynamic of change [3].

The present work is focussed on the kind of highly managed systems located in urban areas of many traditional cities of Central America. Those are private urban greenspaces, called 'patios' in Latin America. The provision of services in the urban context was analysed in previous works [4] with the scope of Swedish cities, but the characteristics and urbanization in tropical American areas makes the comparison of both models difficult.

The study identifies the main services provided by patios that the population perceived as important for their wellbeing in the town of León (Nicaragua) and also analyses habitat and resources provision for wildlife. In a second step, services were quantified considering different groups in relation to patio size and typology. Finally, a discussion about the contribution of patios to human wellbeing, the consequences of fragmentation processes in services provision and the possibilities of newly identified services in the case of tourism promotion, is proposed.

\section{Study area and sampling method}

The town of León is located in western Nicaragua, in an area with a dry tropical climate $-1,484 \mathrm{~mm}$ of average annual rainfall and a mean temperature of $27.5^{\circ} \mathrm{C}$ [5] - $109 \mathrm{~m}$ above the sea level. It is the second city of the country in terms of population size, with 174,051 inhabitants in 2005 [6] and a growth rate in the period 1995-2005 of 7.2\%. The urban structure shows the influence of a prevalent scheme with two original central nuclei, which had implications in patio structure and composition. The colonial and indigenous types of patios are the extremes of a range of cases that can be still recognised nowadays [7].

The sampling design consisted of a stratified method, choosing 16 urban blocks randomly in the two sectors of the historical ground of the City (eight blocks in each, Figure 1). The new neighbouring areas built in the 20 th century were not included. In each selected block all plots were visited to determine the presence-absence of patios, the approximate size of each one and the observed typology (only differentiating colonial and indigenous patios from other typologies). Patios were classified by size ranges and typology, with high (more than $500 \mathrm{~m}^{2}$ ), medium (between 150 and $500 \mathrm{~m}^{2}$ ) and low (less than $150 \mathrm{~m}^{2}$ ) surfaces for the indigenous type and high (more than $100 \mathrm{~m}^{2}$ ) and low (less than 
$100 \mathrm{~m}^{2}$ ) surfaces for the colonial type. The final sample of 40 patios was obtained choosing randomly eight patios in those 16 blocks belonging to each surface group and typology.

Plot divisions between the original state and 2001 were studied using the information provided by the City Mayoralty [8] in two maps that were digitalized in GIS Software. Analyzed blocks were confirmed from 1610 to 1900 and include only the ones at the historical centre. The original configuration compared with the state at 2001 shows the dynamic of plot divisions.
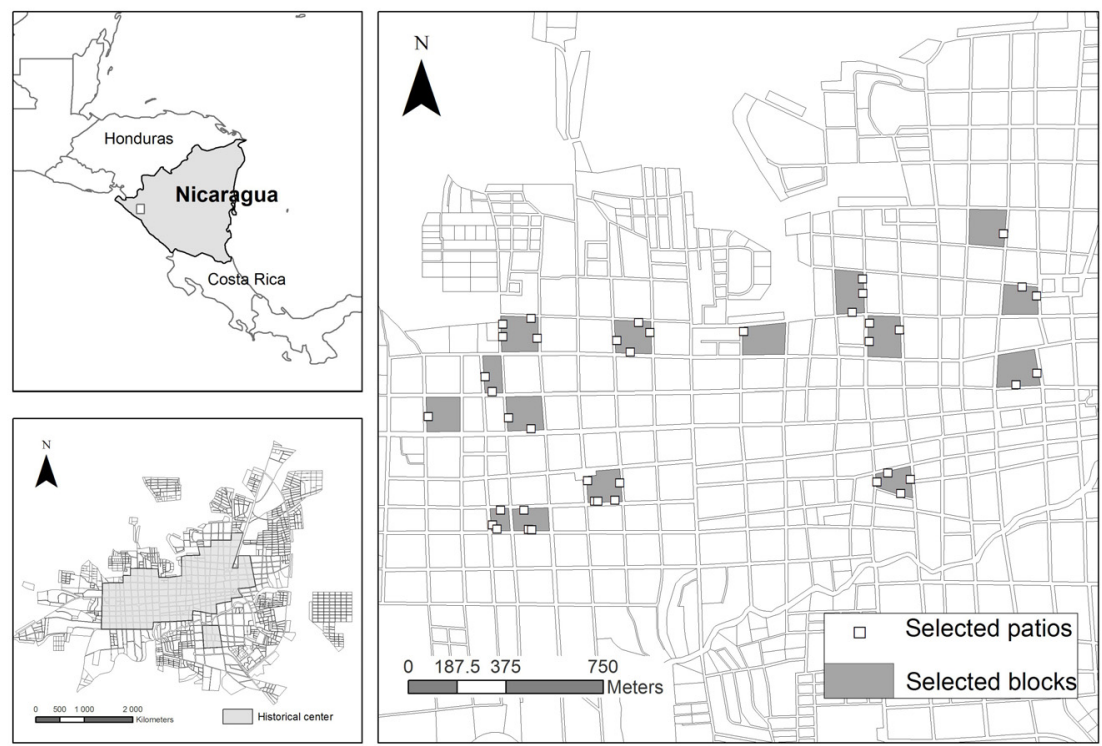

Figure 1: $\quad$ Situation of León City in Nicaragua, Central America (top left map); limits of the studied area, the historical extent of the town (bottom left); and situation of the 16 selected blocks and 40 selected patios (right map).

To study the functions of patios, inhabitants were firstly requested to identify the main reasons for preserving the patio surface and contents. Once these results were obtained and analysed, 11 indicators were established in all of the four groups of services described in literature (see section 3). The variables sampled in the selected patios were related with the physical structure (surface, paved area, kind of fencing...), microclimatic conditions (air temperature and relative moisture), vegetation structure and composition (diversity and uses, life forms, mean cover and height of herbaceous plants, shrubs and trees respectively; the presence of uncultivated woody seedlings,), domestic animals (with emphasis on those useful for human consumption), wild animals (diversity and abundance of birds and abundance of spiny-tailed iguana (Ctenosaura similis) a species very 
appreciated as food) and patio uses (role of patio in daily activities, average time spent for each inhabitant).

\section{Main services provided by patios}

The Millennium Ecosystem Assessment [1] classified services into four groups: supporting, provisioning, regulating and cultural. Supporting services - such as nutrient cycling, soil formation or habitat provision - have a basic status, because they allow the development of the three remaining groups. People do not use directly supporting services, so this group is not perceived as important for patio owners or users. In relation to the rest of the groups, citizens consider the following functions important:

- $\quad$ Fruit and medicinal plant production (provisioning).

- Animals bred for direct consumption (provisioning).

- Reduction of temperature fluctuations (regulation).

- $\quad$ Spaces to stay, leisure and carrying out daily activities (cultural).

With that information and the addition of the supporting group, a total of 11 indicators were established for the study (see Table 1).

Table 1: $\quad$ Indicators used to measure services provision.

\begin{tabular}{|c|c|c|}
\hline Group & Indicator & Measure \\
\hline \multirow[t]{3}{*}{ Provisioning } & $\begin{array}{l}\text { Diversity of fruit and } \\
\text { vegetables }\end{array}$ & $\begin{array}{l}\text { Number of species used for fruit consumption and } \\
\text { vegetables }\end{array}$ \\
\hline & $\begin{array}{l}\text { Market price of fruit and } \\
\text { vegetable production }\end{array}$ & $\begin{array}{l}\text { Price ( } € / \text { year) of the production of fruit and } \\
\text { vegetables grown }\end{array}$ \\
\hline & $\begin{array}{l}\text { Market price of animals } \\
\text { for consumption }\end{array}$ & $\begin{array}{l}\text { Price ( } € / \text { year) of the production of animals for } \\
\text { consumption }\end{array}$ \\
\hline \multirow[t]{3}{*}{ Regulation } & $\begin{array}{l}\text { Air relative moisture } \\
\text { index }\end{array}$ & $\begin{array}{l}\text { Differences between mean \% of humidity inside the } \\
\text { patio and } \% \text { of humidity outside the dwelling }\end{array}$ \\
\hline & Air temperature index & $\begin{array}{l}\text { Difference between mean air temperature }\left({ }^{\circ} \mathrm{C}\right) \text { inside } \\
\text { the patio and temperature obtained outside the } \\
\text { dwelling }\end{array}$ \\
\hline & Percentage of tree cover & $\begin{array}{l}\text { Percentage of the patio surface that is covered by } \\
\text { trees }\end{array}$ \\
\hline Cultural & $\begin{array}{l}\text { Average number of hours } \\
\text { spent by inhabitant }\end{array}$ & $\begin{array}{l}\text { Number of estimated hours that each inhabitant } \\
\text { spends in the patio or in the corridors of it }\end{array}$ \\
\hline \multirow[t]{4}{*}{ Supporting } & Wild bird diversity & Shannon index of observed wild birds \\
\hline & Wild bird abundance & Number of different wild birds observed \\
\hline & Iguana presence & $\begin{array}{l}\text { Patios were spiny-tailed iguanas were frequently } \\
\text { observed by inhabitants }\end{array}$ \\
\hline & Woody seedling richness & $\begin{array}{l}\text { Number of species of woody plants that appear as } \\
\text { spontaneous seedling }\end{array}$ \\
\hline
\end{tabular}

\section{Implications of patio fragmentation}

\subsection{Pattern of pPlot distribution in León town}

The spatial analysis (using a GIS programme) of pPlot division changes between the original arrangement and the situation at 2001 (Figure 2) reveals that each 
original urban pPlot was divided in an average of four derived pPlots, dissimilar in extent. Consequently a reduction of the original mean surface also. At block level $(n=75)$ surface reduction varies between no reduction (one case) and $89.28 \%$. Also, the $91 \%$ of studied blocks shows a reduction of original pPlots higher than $60 \%$ of their surface.
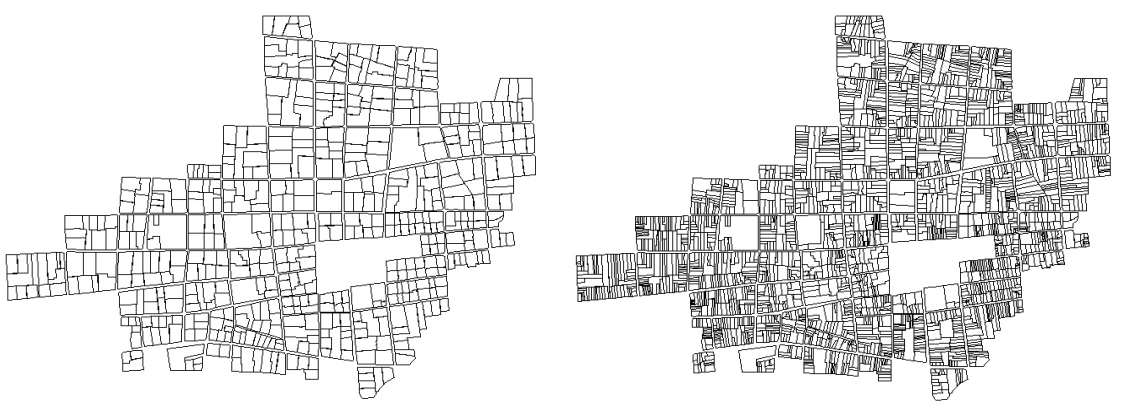

Figure 2: $\quad$ Comparison between the original state of pPlot configuration (left) and the divisions made up to 2001 (right) in 75 blocks of the historical centre of León town. Data source: OCHU [8].

Table 2: $\quad$ Presence of patios in 16 sampled blocks of León city ( 8 blocks in each city sector) and number of patios observed in each surface interval.

\begin{tabular}{|l|l|l|l|}
\hline & Indigenous & & Colonial \\
\hline Plots (n) & 285 & Plots (n) & 383 \\
\hline Plots/Block & 35.63 & Plots/Block & 47.88 \\
\hline Plots with patio & $186(65.26 \%)$ & Plots with patio & $191(49.87 \%)$ \\
\hline Plots without patio & $16(5.61 \%)$ & Plots without patio & $94(24.54 \%)$ \\
\hline Plots without data & $78(27.37 \%)$ & Plots without data & $93(24.28 \%)$ \\
\hline Vacant Plots & $5(1.75 \%)$ & Vacant Plots & $5(1.31 \%)$ \\
\hline Patios & & Patios & \\
\hline Communal or shared patios & $9(5.39 \%)$ & Colonial patios & $114(59.69 \%)$ \\
\hline Low surface a & $79(47.31 \%)$ & Other typologies & $77(40.31 \%)$ \\
\hline Medium surface & $61(36.53 \%)$ & Low surface (colonial) & $99(86.84 \%)$ \\
\hline High surface & $27(16.17 \%)$ & High surface (colonial) & $15(13.16 \%)$ \\
\hline
\end{tabular}

Among the 668 identified plots in the 16 visited blocks, 171 of them have no information regarding approximate plot size and patio presence $(25.60 \%$ of missed information, Table 2). If we don't consider this missed information, the proportion of dwellings having a patio is $89.86 \%$ in the indigenous old city (Sutiaba quarter) and $65.86 \%$ in the colonial style zone (historical centre). Both areas show similar presence of vacant Plots (less than $2 \%$ ). In relation to patio surface, the study shows that the proportion of plots with high extent patios (similar to their original state or showing little reductions) is $16.17 \%$ in Sutiaba and $13.16 \%$ in the centre (Table 2). We can also observe a little proportion of blocks in Sutiaba which dwellings still maintain a common use of a wide and open plot placed in the central part of the block. These cases correspond to a 
former situation in which a commonly owned patio was not divided nor fenced. In the historical centre, $60 \%$ of patios maintain a part of the colonial typology (originally a central patio encircled by four peripheral corridors roofed with Spanish tile, that connect with rooms and other dependencies) and the rest of patios have lost this configuration.

Table 3: Indicators of services provision in 40 patios in León city grouped according to their typology and relative size.

\begin{tabular}{|l|l|l|l|l|l|}
\hline & \multicolumn{2}{|c|}{ Colonial } & \multicolumn{3}{c|}{ Indigenous } \\
\hline Surface group & \multicolumn{1}{|c|}{ High } & \multicolumn{1}{c|}{ Low } & \multicolumn{1}{c|}{ High } & Medium & Low \\
\hline Diversity of fruit and vegetables & 5.75 & 1.13 & 21.00 & 8.50 & 4.00 \\
\hline $\begin{array}{l}\text { Market price of fruit and } \\
\text { vegetables production }\end{array}$ & 131.79 & 28.34 & 586.87 & 248.97 & 108.81 \\
\hline Market price of animals bred $^{\text {Relative humidity index }}{ }^{\mathrm{a}}$ & 0.00 & 0.00 & 49.92 & 43.08 & 9.48 \\
\hline Air temperature index $^{\mathrm{b}}$ & 24.76 & 18.00 & 37.76 & 27.62 & 41.80 \\
\hline Percentage of tree cover & 59.39 & 66.25 & 54.11 & 70.18 & 55.71 \\
\hline Number hours/habitant & 31.67 & 17.54 & 44.36 & 43.41 & 61.72 \\
\hline Wild bird diversity & 4.21 & 2.93 & 4.20 & 4.23 & 4.13 \\
\hline Wild bird abundance & 1.29 & 0.43 & 1.29 & 1.08 & 0.78 \\
\hline Iguana presence & 11.88 & 8.75 & 14.13 & 7.25 & 4.13 \\
\hline Woody seedling richness & 42.86 & 14.29 & 100.00 & 85.71 & 71.43 \\
\hline
\end{tabular}

${ }^{\mathrm{a}}$ Values closer to 100 indicate that humidity inside patio is much higher than the exterior value.

${ }^{\mathrm{b}}$ Values closer to 100 indicate that air temperature inside patio is much higher than the exterior value.

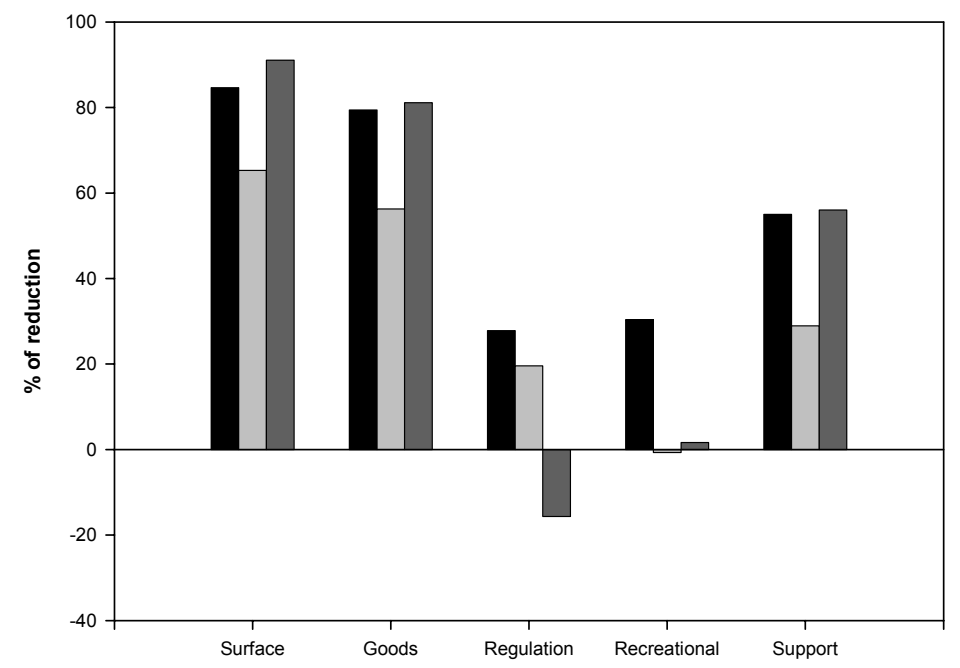

Figure 3: Average percentage of services reduction compared to the undivided patios (colonial and indigenous). 


\subsection{Differences in services provision}

Data taken in 40 patios of different extent and typology show that a reduction in mean surface implies a reduction in the services provided (table 3; Figure 3 ). The exception is the provision of regulation and cultural/recreational services in indigenous patios (Figure 3). Mean surface values obtained were $178.3 \mathrm{~m} 2$ for large and $27.4 \mathrm{~m} 2$ for small colonial patios; and $870.8 \mathrm{~m} 2$ for large; $302.4 \mathrm{~m} 2$ for medium, and $78.0 \mathrm{~m} 2$ for small indigenous patios.

In relation to the provision of goods, the analysed colonial patios had a low production of fruit and vegetables and had not raising of animals for food. As Figure 3 shows, surface reduction is highly related with this group and very related with the services studied. Concerning regulation services a reduction of microclimate regulation is appreciate in colonial patios (augment of mean temperatures and decrease of humidity) but we didn't obtain interpretable results for indigenous ones. The period that each inhabitant spent in the patio is similar in all groups (up to 4 hours) with the exception of low surface colonial patios (Table 3). Finally, support services show a decrease of all indicators in relation to surface reduction, but not as high as the one of goods provision services.

\section{Discussion}

\subsection{Fragmentation processes and services provision}

The transformation of the urban network in León (Nicaragua) has implied a continuous division of original plots at the historical centre that supposes a problem for the conservation of the original structure of the valuable colonial type houses. Causes of this phenomenon are related to difficulties for families to maintain houses with high surface and for descendants (new inhabitants) to have their own housings. The increase and densification of urban plot implies the construction of new rooms in detriment of the patio surface. At the indigenous rooted quarter of the town data of plot divisions are not available, but the visits show a parallel fragmentation process. In this case only $16 \%$ of patios have preserved the main part of their original surface.

Looking at environmental services supplying, provisioning and supporting groups are significantly linked to surface reduction, but there is no clear associations of the regulation and cultural groups. Nevertheless, the rate of reduction in surface is always higher than the rate of reduction of services evaluated, then, we could conclude that the process has not reached the threshold from which the services fall down faster than surface or disappear.

Considering both typologies of patio analyzed, the higher surface of indigenous patios allows them to supply a higher amount of services than colonial ones. Also the vegetation structure and plant composition (diversity, dominance) is important to evaluate environmental services in both groups [7]. Indigenous-root patios tend to have a multi-stratified vegetation cover where trees can reach 20 meters high and the composition evokes the tropical dry forests that surrounds the town. Colonial patios have less presence of native trees 
and a management of flora destined primarily to ornamental purposes. Due to this, presence of some animals that are dependent to specific plants (mostly natives) is reduced, as is the case of spiny-tailed iguana. The richness and abundance of mobile vertebrates such as wild birds did not reduce, but the species present and their relative abundance in both cases are different.

The cultural services were represented with the mean amount of time that each inhabitant spends at the patio or its corridors for different purposes. All kinds of patio show similar values of this indicator with the exception of low surface colonial ones. In colonial dwelling, the space that the corridors occupy is reduced, not allowing the normal development of daily activities (for instance to place tables and chairs as occurs in well conserved corridors). The expansion of new rooms occupying the patio leaves a corridor that sometimes have less than $50 \mathrm{~cm}$, and its function changes from a place to staying and labouring to a place linking different rooms of the house. In that case, the process of continuous division has changed the functionality of patios and, according to the inhabitant's opinion, removed the function having a higher influence on their life quality. At the indigenous-root patios, inhabitants use this space to live inside (that is not so frequent in colonial patios) and even the low surface patios have enough space to keep up that function $\left(78 \mathrm{~m}^{2}\right)$.

In relation to regulation services, patios play an important role in the creation of comfortable conditions in specific periods of the day. In all analysed groups air temperature inside patios were lower that value obtained close outside and mean difference in 40 patios is 1.1 degrees centigrade. Air humidity values are also higher in all patio groups, with a mean difference of $4.66 \%$. When all patios are compared and surface is tested to find a decrease in this service, correlation doesn't emerge. Climate regulation can be maintained according to the kind of division carried out. We founded that patios divided with 'permeable' fencing methods, such as live fences, wire fences or walls lower than 2 meters, can maintain this service properly.

\subsection{An unexploited service: tourism promotion}

Cultural services include also the recreation and ecotourism activities. Recreation services can be measured in part through the mean spent in the patio, but tourism possibilities is an unexploited service that can enhance the importance of patios, as well as their esteem and usefulness for inhabitants [9]. An initiative aimed to reinforce tourism services was to establish guided tours in patios with participation and benefit to owners or inhabitants [10]. Developing guided visits to the patios have a direct economic impact to owners, local guides, tourist companies, academic researchers (history, ecology, etc) and an indirect impact to the city by prolonging the time of staying of tourists.

Each visit to patios needs to compile at least 15 tourists, and the prices vary between national tourists $(1.1$ dollar/person) and foreign tourists (5 dollars/person). The profit is divided in equal shares between the guide and the patio owners. Table 4 explores the possibilities of this initiative in function of the success of it, supposing that each visit have the minimum tourists (15) and 5 of 
Table 4: $\quad$ Obtained earnings in the patio guided tours supposing 1 to 4 visits each month.

\begin{tabular}{|c|c|c|}
\hline Number of visits/year & Income to guide $(€ /$ year) & Income to each owner $(€ /$ year) \\
\hline 12 & 209 & 19 \\
\hline 24 & 418 & 38 \\
\hline 36 & 627 & 57 \\
\hline 48 & 836 & 76 \\
\hline
\end{tabular}

them are national. If the objectives of the organizers are reached (to ensure at least 2 visits each week, with a maximum of 4), earnings could reach an interval of 3,34-6,68 €/year (152-304 €/year to each patio owner).

Recreation and tourism uses of ecosystems are growing worldwide [1], with considerable development of infrastructures. Tourism growth is a reality in Nicaragua, were visitors increased 55\% between 2002 and 2006, and earnings increased $98 \%$ in the same period [11]. Visits to private patios are not an expensive initiative, located inside of a historical town with a high possibility of expanding to other cities with a valuable heritage throughout the world. This initiative has a very distributed economic impact and can contribute to preserve important environmental services (biodiversity, vegetation cover, marketable commodities) for the whole society.

\section{Concluding remarks}

The study shows that a very special part of the family dwelling in Central America, as is the patio can provide a considerable range of services. Patio is as the same time the quotidian human habitat and a source of several resources. Following the same way of many cities in developing countries León is suffering a process of plot densification, so the original characteristics and functions of patios are threatened of disappearing or degrading. The two groups of services that are strongly correlated to patios fragmentation are provisioning and supporting. As supporting services are in the base of the rest groups, the descent of them can quickly collapse the rest of the groups. In relation to cultural services, it seems clear that a condition of conservation is of to improve the awareness of the patio owners. Investigating, documenting and monitoring environmental services is an efficient tool to direct economic support and new initiatives to patios.

\section{References}

[1] Millennium Ecosystem Assessment, Ecosystems and Human Well-being: Synthesis, Island Press: Washington, DC, 2005.

[2] Costanza, R., d'Arge, R., de Groot, R., Farber, S., Grasso, M., Hannon, B., Limburg, K., Naeem, S., O’Neill, R.V., Paruelo, J., Raskin, R.G., Sutton, P., \& van den Belt, M., The value of the world's ecosystem services and natural capital. Nature, 387, pp. 253-260, 1997. 
[3] Chee, Y.E., An ecological perspective on the valuation of ecosystem services. Biological Conservation, 120(4), pp. 549-565, 2004.

[4] Bolund, P. \& Hunhammar, S., Ecosystem services in urban areas. Ecological Economics, 29(2), pp. 293-301, 1999.

[5] Instituto Nicaragüense de Estudios Territoriales (INETER), Atlas Climático de Nicaragua, Dirección General de Meteorología, Managua, 2004.

[6] Instituto Nacional de Información de Desarrollo (INIDE), http://www.inec.gob.ni/

[7] González-García, A. \& Gómez-Sal, A., Private urban greenspaces or "patios" as a key element in urban ecology of tropical Central America. Human Ecology, 36(2), pp. 291-300.

[8] Oficina de Centro Histórico y Urbanismo (OCHU), Plan especial de revitalización del centro de León: Estudio base tipológico-urbanoarquitectónico, Alcaldía de León, León, 2001.

[9] Gómez Sal, A., González García, A., Santovenia Pérez, C. \& Dávila Prado, P., Private patios, a valuable hidden heritage for tourism development in the city of León, Nicaragua. Sustainable Tourism II, ed. C.A. Brebbia \& F.D. Pineda, WIT Press: Southampton and Boston, pp. 85-93, 2006.

[10] Santovenia Pérez, C., Los patios leoneses, una oportunidad para el turismo cultural y el turismo de naturaleza. Los patios de León (Nicaragua): Naturaleza y Patrimonio, ed. A. González García \& A. Gómez Sal, Universidad de Alcalá: Alcalá de Henares, pp. 111-148.

[11] Instituto Nicaragüense de Turismo (INTUR), Boletín de Estadísticas del Turismo, Managua, 2006. 